\title{
Comparing interview and trade data in assessing changes in the seahorse Hippocampus spp. trade following CITES listing
}

\author{
Joy T.L. Lam, Heather J. Koldewey, Maï Yasué and Amanda C. J. Vincent
}

\begin{abstract}
Concerns regarding the sustainability of the seahorse Hippocampus spp. trade led to their listing on CITES Appendix II in 2002, with implementation in 2004. In 2007 we interviewed wholesale traders of seahorses in Hong Kong, China, seeking indications of the effects of the CITES listing on the seahorse trade. We cross-validated traders' perspectives with government trade statistics (1998-2007) from Hong Kong and Taiwan. We also compared these data with trade statistics for pipefish, which are related species with similar medicinal uses but are not CITES-listed. Both the interviews and government statistics indicated reduced volumes of seahorses traded through Hong Kong, changes in source countries, and price increases post-implementation. Traders suggested that these changes were largely a result of the CITES listing. However, data indicate that other factors such as shifts in domestic policies and local demand may also have affected the trade. By cross-validating the perspectives of local stakeholders with trade statistics in a wildlife trading hub we were able to explore hypotheses on the local and global impacts of CITES. Such approaches are especially important for CITES-listed species because often there is no single data source that is complete and wholly reliable.
\end{abstract}

Keywords Local knowledge, market surveys, traditional Chinese medicine, wildlife trade

This paper contains supplementary material that can be found online at http://journals.cambridge.org

\section{Introduction}

7 he Convention on International Trade in Endangered 1 Species of Wild Fauna and Flora (CITES) is a multilateral environmental agreement established to ensure that international trade does not threaten species of flora

JoY T.L. LAM*, MAÏ YASUÉ† (Corresponding author) and AMANDA C.J. VINCENT Project Seahorse, Fisheries Centre, University of British Columbia, 2202 Main Mall, Vancouver BC, V6T 1Z4, Canada. E-mail maiyasue@gmail.com

Heather J. Koldewey Project Seahorse, Zoological Society of London, Regent's Park, London, UK

*Also at: University of Hong Kong, Hong Kong, China $\dagger$ Also at: Quest University Canada, Squamish, Canada

Received 1 August 2013. Revision requested 25 November 2013. Accepted 18 March 2014. First published online 21 October 2014. and fauna. Species are listed in one of three Appendices to the Convention according to their conservation status and the perceived level of threat from international trade (Reeve, 2006). Species listed in Appendix II are not at immediate risk of extinction but may become threatened if trade is not adequately controlled (Article II; CITES, 1979). In theory, being listed in Appendix II improves the health of wild populations because Parties to the Convention must ascertain that trade does not threaten wild populations or their role in the ecosystem (Article IV; CITES, 1979). National management authorities are required to authorize exports of specimens through permits, ensure that exported specimens were obtained in accordance with domestic laws, and submit annual trade reports to the CITES Secretariat.

Little is known about how CITES listings actually affect wildlife populations, dependent human communities or the trade of particular species (Smith et al., 2011; Poh \& Fanning, 2012). This is because most countries do not have pre-listing baseline trade data from which to assess what might have happened to a species had it not been listed (Ferraro \& Pattanayak, 2006). Furthermore, there are few cases in which the trade of a CITES-listed species can be compared to non-listed, taxonomically and ecologically similar taxa (Ferraro et al., 2007).

Even after a species has been listed by CITES the quality of data collected by management authorities varies. Global wildlife trade is complex and difficult to monitor, with multiple stakeholders from different countries working within different laws. In regions with limited enforcement (Nijman \& Shepherd, 2007) and limited support for CITES from people involved in the trade, trade records may be incomplete as a result of a desire to save time, avoid taxation or conceal illicit trade routes (Blundell \& Mascia, 2005).

Enforcement can be particularly difficult in the trade of marine species because the trade and exploitation are often geographically widespread (Doukakis et al., 2009) and species may be difficult to identify (Foster \& Vincent, 2005). Given the potential for trade to harm biodiversity (Shuman et al., 2005), and the fact that in some countries CITES may be one of the few legal instruments for protection of biodiversity, there is a need to identify more robust and costeffective approaches to evaluate, monitor and improve the effects of CITES on wildlife and on the people who depend on traded species.

In November 2002 seahorses Hippocampus spp. became the first marine fishes to be listed in Appendix II since the 
inception of CITES, with the listing entering into force in May 2004. Seahorses were listed because of concerns that their exploitation to support the global demand for medicinal use, aquariums and curiosities could harm populations that were also threatened by incidental fisheries by-catch and habitat degradation (Vincent, 1996; Vincent et al., 2011).

Here we assess the possible effects of CITES listing on the trade of seahorses for traditional Chinese medicine in Hong Kong, China. Seahorses are among the most heavily traded species (by number of individuals) under CITES regulation and are an important ingredient in traditional Chinese medicine (Zhang et al., 2000). Although $>80$ countries are involved in the dried-seahorse trade (Evanson et al., 2011) we focused on Hong Kong because almost half of the reported global trade prior to the CITES listing entered Hong Kong, both for domestic consumption and for re-export to ethnic Chinese communities worldwide (Evanson et al., 2011).

We examine and compare the perspectives of local stakeholders with formal trade statistics to identify strengths and weaknesses of each data set and to examine the apparent local effects of CITES in Hong Kong (Burkhart et al., 2012). Traders have valuable insights into these effects because they must integrate diverse sets of information to assess how local or international policies affect their business (Winter et al., 2011). The trade statistics we examined included pre-listing and post-implementation statistics for Hong Kong and also for Taiwan, where seahorses are also used in traditional medicine, as well as concurrent trade data for pipefish. We used pipefish to discriminate between CITES and non-CITES-related changes in trade patterns because pipefish are near relatives of seahorses and are traded in a similar manner but are not listed by CITES.

\section{Methods}

We used three approaches to assess the ramifications of a CITES listing for the trade of seahorses through Hong Kong. Firstly, we drew on our long-standing (since 1998) collaborative dialogue with traders in the traditional Chinese medicine community in Hong Kong to conduct interviews with wholesale traders about their perceptions of changes in the seahorse trade with the advent of the CITES Appendix II listing. Some perspectives were based on many years of experience of the trade (since before 1998).

Secondly, we used trade data from the Hong Kong Census and Statistics Department, collected since 1998 (6 years before CITES regulations for seahorses came into effect), for seahorses and pipefish. Thirdly, we examined trade data for seahorses from the Taiwanese government (collected since 1982). We did not use formal CITES data because they did not cover the period before CITES implementation and were incomplete for several years thereafter.

\section{Trade interviews}

During April-October 2007 we conducted semi-structured interviews with the owners $(\mathrm{n}=9)$ and an operations manager $(n=1)$ of traditional Chinese medicine trading companies in Hong Kong. These comprised five import/export/wholesale companies, four import/export/ wholesale/retail companies and one wholesale/retail company. All the interviews were conducted in Cantonese by JTLL, a native of Hong Kong. The respondents were all members of the Hong Kong Chinese Medicine Merchants' Association, the main business trade association for traditional Chinese medicine in Hong Kong.

These 10 companies had been trading seahorses for 9-30 years and had been identified in previous market surveys during 1993-1995 (Vincent, 1996) or 1998-2000 ( $n=9$, A.C.J. Vincent, pers. obs.) or through the local traditional Chinese medicine community $(\mathrm{n}=1)$ as trading large quantities of dried seahorses.

Interviews were conducted in person and lasted 30-120 minutes, depending on the level of knowledge and interest of the respondent. Prior to interview, all wholesale traders who had been identified as key seahorse traders in previous studies were contacted and consents were obtained before any meetings took place. Our semi-structured questions focused on (1) the trader's knowledge of CITES, (2) changes in trade routes, supply, value and demand following CITES listing of seahorses, and (3) perceptions about costs and effectiveness. Throughout the results we indicate how many of the traders (n) expressed a particular viewpoint.

The study received human ethics research approval from the University of British Columbia and the University of Hong Kong.

\section{Trade statistics}

On 15 July 2011 we obtained annual trade statistics (volume and economic value) for seahorses and pipefish, for 1998-2007, from the Hong Kong Census and Statistics Department. Businesses and traders are required by Hong Kong law to declare all cross-border trade to the Census and Statistics Department within 3 months of the trade, for research and planning purposes. We analysed Country of Origin of imports. This is the country where the product was produced in its entirety or underwent the last substantial transformation. Import volumes listed under Countries of Origin include volumes that were imported and sold within Hong Kong, as well as volumes that were 
TABLE 1 Summary of trade routes from seahorse Hippocampus spp. source countries to consumers in 1993-1995, 1998-2001 and 2007, based on the responses of traders ; ${ }^{\star}$ indicates years in which these trade routes were suggested by respondents. The routes specified for $1993-1995$ and 1998-2001 are based on unpublished market surveys. Traders are traditional Chinese medicine traders unless otherwise specified.

\begin{tabular}{|c|c|c|c|c|c|c|c|}
\hline Source country & 1 st import ${ }^{1}$ & 2nd import & Wholesale & Retail & 1993-1995 & $1998-2001$ & 2007 \\
\hline \multirow[t]{7}{*}{ Various (legal) } & Hong Kong $(\mathrm{n}=5)$ & & Hong Kong & Hong Kong or & * & * & * \\
\hline & & & & Mainland China & & & \\
\hline & Hong Kong $(\mathrm{n}=2)$ & $\begin{array}{l}\text { Mainland China, } \\
\text { North America }\end{array}$ & & Other & * & * & * \\
\hline & $\begin{array}{l}\text { Hong Kong } \\
\text { (Seafood traders; } \\
\mathrm{n}=2 \text { ) }\end{array}$ & & Hong Kong & Hong Kong & & * & * \\
\hline & $\begin{array}{l}\text { Mainland China } \\
(\mathrm{n}=2)\end{array}$ & $\begin{array}{l}\text { Mainland China } \\
\text { or Hong Kong }\end{array}$ & $\begin{array}{l}\text { Mainland China } \\
\text { or Hong Kong }\end{array}$ & Hong Kong & * & & * \\
\hline & Taiwan $(\mathrm{n}=2)$ & $\begin{array}{l}\text { Mainland China } \\
\text { or Hong Kong }\end{array}$ & $\begin{array}{l}\text { Mainland China } \\
\text { or Hong Kong }\end{array}$ & Hong Kong & & & * \\
\hline & $\begin{array}{l}\text { Mainland China, } \\
\text { North America, } \\
\text { Taiwan }(n=1)\end{array}$ & & $\begin{array}{l}\text { Mainland China, } \\
\text { North America, } \\
\text { Taiwan }\end{array}$ & $\begin{array}{l}\text { Mainland China, } \\
\text { North America, } \\
\text { Taiwan }\end{array}$ & & & * \\
\hline $\begin{array}{l}\text { Countries with } \\
\text { domestic bans }\end{array}$ & $\begin{array}{l}\text { High seas transfer } \\
(\mathrm{n}=1)\end{array}$ & Mainland China & Mainland China & Mainland China & & & * \\
\hline
\end{tabular}

${ }^{1}$ Sample sizes (n) are for 2007 surveys.

subsequently re-exported to other countries. We used USD $1=$ HKD 7.8 in all calculations.

Because our study focused on comparing sources of data, we include trade data only until 2007, when we interviewed the traders. We refer throughout to three time periods relative to the CITES listing and its implementation: pre-listing, 1998-2001; transition, 2002-2004; and postimplementation, 2005-2007. The transition period refers to the time between the listing of seahorses and the implementation of the listing. We did not include data from the transition period in the pre-listing period because traders may have been becoming aware of the impending implementation of the CITES listing and may have started to change their behaviour.

We obtained statistics for the seahorse trade to and from Taiwan during 1998-2007 from the General Administration of Customs of the People's Republic of China. These included country of origin and import values (reported in USD).

We also examined the trade statistics to assess how domestic bans on the trade and exploitation of seahorses affected the seahorse trade. In 2001, before the CITES listing, India banned the trade and exploitation of seahorses and pipefish by placing syngnathids under Schedule I of the Indian Wildlife Protection Act 1972 (Sreepada et al., 2002; Lourie et al., 2004). In 2004 Peru and the Philippines banned seahorse exploitation and export because of the Appendix II listing (Christie et al., 2011).

Because our primary goal was to compare the perspectives of the traders with the trade statistics, here we focus only on trade statistics (Tables 1-3) that were relevant to the perspectives and concerns of the traders. The complete raw data are available in Supplementary Tables $\mathrm{S}_{1}-\mathrm{S}_{5}$. We investigated statistical differences between pre-listing and post-implementation trade statistics, using non-parametric Kruskal-Wallis one-way ANOVA (analysis of variance) in $R$ v. 3.1 (R Development Core Team, 2012). In addition to these statistical analyses we present descriptive data of mean values (and percentage changes) of the trade statistics for pre-listing and post-implementation (Tables 2 and 3 ).

\section{Results}

\section{Trade interviews}

Knowledge about CITES All respondents had a basic understanding of the general objectives of CITES. They were familiar with the procedures for obtaining export permits locally from the Agriculture, Fisheries and Conservation Department, the official CITES management authority for Hong Kong. Traders (especially those active in trade associations) met regularly with officers of the Management Authority to discuss updates in CITES listings and regulation controls or were informed of changes in policy through their industry associations $(n=5)$. Four of the traders were aware of the $10 \mathrm{~cm}$ minimum size limit for seahorses in trade, recommended by the Animal Committee of CITES in April 2004 as an interim precautionary measure (CITES, 2004; Foster \& Vincent, 2005). However, one of these traders believed that it was a maximum size limit. One of the traders believed that the trade ban in India was a consequence of CITES whereas, although it had its origins in CITES deliberations, the ban actually pre-dates the CITES listing. 
TABLE 2 Hong Kong (Census and Statistics Department) and Taiwan (General Administration of Customs of the People's Republic of China) government trade statistics for seahorses and pipefish in Hong Kong and seahorses in Taiwan before the genus was listed in CITES Appendix II (1998-2001) and after implementation of the listing (2005-2007).

\begin{tabular}{|c|c|c|c|c|c|c|c|c|c|c|c|c|}
\hline & \multicolumn{8}{|l|}{ Hong Kong } & \multirow{2}{*}{\multicolumn{4}{|c|}{$\begin{array}{l}\text { Taiwan } \\
\text { Seahorses }(\text { Mean } \pm \text { SD) }\end{array}$}} \\
\hline & \multicolumn{2}{|c|}{ Seahorses $($ Mean \pm SD) } & \multirow[b]{2}{*}{$\chi_{1}^{2}$} & \multirow[b]{2}{*}{$\mathrm{P}$} & \multicolumn{2}{|c|}{ Pipefish $($ Mean \pm SD) } & \multirow[b]{2}{*}{$\chi_{1}^{2}$} & \multirow[b]{2}{*}{$\mathrm{P}$} & & & & \\
\hline & Pre-listing & $\begin{array}{l}\text { Post- } \\
\text { implementation }\end{array}$ & & & Pre-listing & $\begin{array}{l}\text { Post- } \\
\text { implementation }\end{array}$ & & & Pre-listing & $\begin{array}{l}\text { Post- } \\
\text { implementation }\end{array}$ & $\chi_{1}^{2}$ & $\mathrm{P}$ \\
\hline No. of source countries & $12 \pm \mathrm{SD} 3$ & $6 \pm$ SD 1 & 4.9 & 0.03 & $5 \pm$ SD 1 & $4 \pm$ SD 1 & 2.1 & 0.1 & $7 \pm$ SD 1 & $3 \pm$ SD 1 & 4.8 & 0.03 \\
\hline Total imports (kg) & $17,728 \pm \operatorname{SD} 4,958$ & $10,795 \pm$ SD 1,767 & 4.5 & 0.03 & $13,667 \pm \operatorname{SD} 5,340$ & $8,120 \pm$ SD 4,951 & 1.1 & 0.3 & $8,066 \pm$ SD 2,368 & $4,542 \pm$ SD 1,964 & 3.1 & 0.08 \\
\hline $\begin{array}{l}\text { Imports from Philippines } \\
(\mathrm{kg})\end{array}$ & $6,019 \pm$ SD 1,139 & $53 \pm$ SD 92 & 4.5 & 0.03 & $4,051 \pm$ SD 1,445 & $3,616 \pm$ SD 513 & 0.01 & 1 & $595 \pm$ SD 393 & 0 & 4.9 & 0.03 \\
\hline Imports from India $(\mathrm{kg})$ & $2,315 \pm$ SD 2,178 & 0 & 3.5 & 0.06 & $4,311 \pm$ SD 5,407 & 0 & 3.1 & 0.08 & 0 & 0 & & \\
\hline Imports from Peru (kg) & $188 \pm 164$ & $128 \pm$ SD 222 & 0.5 & 0.5 & 0 & 0 & & & 0 & 0 & & \\
\hline $\begin{array}{l}\text { Imports from Latin } \\
\text { America/Africa, } \\
\text { excluding Peru (kg) }\end{array}$ & $536 \pm$ SD 110 & $1,247 \pm \mathrm{SD} 308$ & 2 & 0.2 & 0 & 0 & & & $51 \pm S D 102$ & $1,582 \pm$ SD 1,777 & 1.8 & 0.2 \\
\hline $\begin{array}{l}\text { Imports from outside } \\
\text { China }\end{array}$ & $\begin{array}{l}17,687 \pm \text { SD 4,899 } \\
\text { (mainland China } \\
\text { and Taiwan) }\end{array}$ & $10,794 \pm \mathrm{SD} 2,897$ & 4.5 & 0.003 & 0 & 0 & & & $\begin{array}{l}7,548 \pm \text { SD 1,770 } \\
\text { (mainland China } \\
\text { and Hong Kong) }\end{array}$ & $4,535 \pm$ SD 1,953 & 3.1 & 0.08 \\
\hline Price (USD/kg) & $63 \pm \operatorname{SD} 9$ & $128 \pm \mathrm{SD} 31$ & 4.5 & 0.03 & $24 \pm \operatorname{SD} 9$ & $60 \pm$ SD 46 & 2 & 0.2 & $65 \pm 26$ & $41 \pm$ SD 5.8 & 2 & 0.2 \\
\hline Total value ( 1,000 USD) & $1,406 \pm$ SD 242 & $1,342 \pm$ SD 123 & 0.1 & 0.7 & $303 \pm$ SD 81 & $377 \pm$ SD 158 & 0.5 & 0.5 & $497 \pm 137$ & $183 \pm \operatorname{SD} 58$ & 4.5 & 0.03 \\
\hline Total re-export (kg) & $27,692 \pm$ SD 18,458 & $4,417 \pm \mathrm{SD} 2,341$ & 3.1 & 0.08 & $999 \pm$ SD 1,858 & $124 \pm$ SD 120 & 0.13 & 0.7 & & & & \\
\hline Re-export to China $(\mathrm{kg})$ & $13,603 \pm \operatorname{SD} 9,446$ & $10 \pm$ SD 18 & 4.5 & 0.03 & $498 \pm$ SD 930 & 0 & 3.0 & 0.08 & & & & \\
\hline $\begin{array}{l}\text { Re-export to } \\
\text { North America }(\mathrm{kg})\end{array}$ & $114 \pm$ SD 208 & $92 \pm \mathrm{SD} 4$ & 1.1 & 0.3 & $3 \pm \operatorname{SD} 5$ & $124 \pm$ SD 120 & 4.9 & 0.03 & & & & \\
\hline
\end{tabular}


TABLE 3 A comparison between traders' responses and government trade data for changes in seahorse and pipefish trade after implementation of the CITES listing (compared to pre-listing). For the trade statistics, the periods compared are 1998-2001 (pre-listing) and 2005-2007 (after implementation). We used the Census Statistics Department data for Hong Kong and China Customs Statistics data for Taiwan. We did not examine re-export data for Taiwan.

\begin{tabular}{|c|c|c|c|}
\hline \multirow[b]{2}{*}{ Traders' responses } & \multicolumn{2}{|l|}{ Hong Kong trade statistics } & \multirow{2}{*}{$\frac{\text { Taiwan trade statistics }}{\text { Seahorses }}$} \\
\hline & Seahorses & Pipefish & \\
\hline $70-100 \%$ decrease in imports $(n=9)$ & $\begin{array}{l}\text { Total import trade decreased by } 39 \% \\
(6,933 \mathrm{~kg})^{*}\end{array}$ & $\begin{array}{l}\text { Total import trade decreased by } 40 \% \\
(5,545 \mathrm{~kg})\end{array}$ & $\begin{array}{l}\text { Total import trade decreased by } 44 \% \\
(3,523 \mathrm{~kg})\end{array}$ \\
\hline Reduced seahorse supplies from Philippines $(\mathrm{n}=10)$ & $\begin{array}{l}\text { Imports from the Philippines decreased } \\
\text { by } 99 \%(5,965 \mathrm{~kg})^{*}\end{array}$ & $\begin{array}{l}\text { Imports from the Philippines decreased by } \\
11 \%(435 \mathrm{~kg})\end{array}$ & $\begin{array}{l}\text { Imports from the Philippines decreased } \\
\text { from }(595 \mathrm{~kg}) \text { to } 0^{*}\end{array}$ \\
\hline Reduced seahorse supplies from India $(n=10)$ & $\begin{array}{l}\text { Imports from India decreased from } 2,315 \\
\text { to } 0 \mathrm{~kg}\end{array}$ & $\begin{array}{l}\text { Imports from India decreased from } 4,311 \\
\text { to } 0 \mathrm{~kg}\end{array}$ & $\begin{array}{l}\text { No imports from India before or after } \\
\text { implementation }\end{array}$ \\
\hline Stopped importing from outside China $(\mathrm{n}=4)$ & $\begin{array}{l}\text { Imports from outside mainland China } \\
\text { decreased by } 39 \%(6,893 \mathrm{~kg})^{*}\end{array}$ & $\begin{array}{l}\text { No imports from mainland China before or } \\
\text { after implementation }\end{array}$ & $\begin{array}{l}\text { Imports from outside mainland China } \\
\text { decreased by } 40 \%(3,013 \mathrm{~kg})\end{array}$ \\
\hline $\begin{array}{l}\text { Sourced seahorses from Africa \&/or Latin America in } \\
\text { response to reduced supplies from Philippines }(n=2)\end{array}$ & $\begin{array}{l}\text { Imports from Africa/Latin America } \\
\text { increased by } 132 \%(711 \mathrm{~kg})\end{array}$ & $\begin{array}{l}\text { No imports from Africa or Latin America } \\
\text { before or after implementation }\end{array}$ & $\begin{array}{l}\text { Imports from Africa/Latin America } \\
\text { increased by } 3,000 \%(1,531 \mathrm{~kg})\end{array}$ \\
\hline $\begin{array}{l}\text { Prices increased because of CITES-related changes in } \\
\text { supply }(n=4)\end{array}$ & Prices increased by $104 \%\left(\text { USD } 65 \mathrm{~kg}^{-1}\right)^{\star}$ & Prices increased by $153 \%$ (USD $37 \mathrm{~kg}^{-1}$ ) & Prices decreased by $37 \%$ ( $24 \mathrm{USD} / \mathrm{kg}$ ) \\
\hline Hong Kong became less of a re-export hub $(\mathrm{n}=4)$ & $\begin{array}{l}\text { Re-exports decreased by } 84 \% \\
(23,274 \mathrm{~kg})\end{array}$ & Re-exports decreased by $87 \%$ ( 875 kg) & \\
\hline $\begin{array}{l}\text { Decrease in once thriving re-export trade to mainland } \\
\text { China and Taiwan }(\mathrm{n}=6)\end{array}$ & $\begin{array}{l}\text { Re-exports to mainland China \& Taiwan } \\
\text { decreased by } 99 \%(13,592 \mathrm{~kg})^{*}\end{array}$ & $\begin{array}{l}\text { Re-exports to mainland China \& Taiwan) } \\
\text { decreased from } 498 \text { to } 0 \mathrm{~kg}\end{array}$ & \\
\hline Decrease in re-export trade to North America $(n=1)$ & $\begin{array}{l}\text { Re-exports to North America decreased } \\
\text { by } 19 \%(22 \mathrm{~kg})\end{array}$ & $\begin{array}{l}\text { Re-exports to North America increased by } \\
4,873 \%(122 \mathrm{~kg})^{*}\end{array}$ & \\
\hline
\end{tabular}

${ }^{*}$ Denotes changes between pre-listing and post-implementation, where Kruskal-Wallis $\mathrm{P}<0.05$. 
Import supplies and volumes In 2007 all 10 traders suggested that the supply of dried seahorses for traditional Chinese medicine had decreased since the implementation of the CITES listing. They inferred that the decreased supply was linked to domestic restrictions on exploitation and trade in several key source countries: India in 2001 and the Philippines in 2004. Two traders predicted that business would diminish further with such a decrease in supply. Two traders noted that they compensated for reduced supplies of seahorses from the Philippines by sourcing them from Africa and/or Latin America. One trader stated that seahorses may have become increasingly difficult or costly to capture because of overexploitation. Nine of the 10 traders stated that the volume of seahorses traded decreased by $70-100 \%$, and one stated that there was no change over time. Although all traders had previously imported large quantities of seahorses, only two were still actively importing dried seahorses; three others continued to import only minimal quantities compared to pre-listing (before 2002). The biggest importer we interviewed stated that he had imported c. 10 tonnes of dried seahorses annually to Hong Kong pre-implementation but only c. 3 tonnes per year thereafter. Four traders stopped importing from outside China after the CITES listing came into force. They sourced seahorses from local traditional Chinese medicine importers $(n=1)$, seafood importers $(n=2)$ or distributors in mainland China $(\mathrm{n}=2)$, traded stocks that had been acquired prior to CITES listing $(n=1)$ or stopped trading seahorses $(\mathrm{n}=1)$. All of the respondents still trading seahorses said that seahorses were a minor part of their business.

Import price According to the traders interviewed dried seahorses were sorted and sold mainly by size, species, country of origin or whether they were bleached. Two traders suggested that, pre-listing, dried seahorses were considered one of the most profitable products in traditional Chinese medicine trade on a per-item basis. According to the traders, in 2007 mean import/re-export prices for small and large seahorses were USD 256 and $513-641 \mathrm{~kg}^{-1}$, respectively. Three traders noted that they were trading smaller seahorses than before the CITES listing came into force. Four traders suggested that the increase in import prices was caused by a CITES-related reduction in supply. The high import values and low supplies of dried seahorses led to lower profits compared to pre-implementation $(\mathrm{n}=8)$.

Demand for seahorses in mainland China and Hong Kong According to four traders, demand for seahorses in mainland China had been increasing since 2002 and exceeded supply. In contrast, two traders in Hong Kong predicted a decline in local demand for traditional Chinese medicine because younger people in Hong Kong increasingly prefer western medicine.
Re-export destinations and trade routes Traders reported that the thriving re-export industry from Hong Kong to mainland China and Taiwan decreased postimplementation $(n=6)$. Instead there was a more direct trade from source countries to mainland China $(n=4)$ and Hong Kong was a less important re-export hub after the implementation of CITES $(n=4)$. Three traders suggested that stricter CITES implementation in Hong Kong than in mainland China led to more direct trade to mainland China. The two traders who were still importing significant quantities of dried seahorses in 2007 said that $70 \%$ of their products were re-exported to mainland China. One trader also suggested that the re-export of seahorses to North America had declined because, post-implementation, North American countries imported dried seahorses directly from South America at a considerably cheaper price than from Hong Kong. During the interviews, traders indicated that the number of trade routes had increased after the listing of seahorses, and two of the new trade routes did not involve Hong Kong as an importer of dried seahorses (Table 1).

Perceptions of CITES effectiveness Four traders noted that the CITES permitting procedures in Hong Kong require too much time to obtain permits and perform stock checks, with negative effects on profit margins. Smaller traders in particular perceived a greater time investment to comply with CITES. As a result, they traded fewer seahorses or restricted their focus to local sales. Seven traders expressed concern over the increased number of species for traditional Chinese medicine that are controlled by CITES. In particular, they worried that if lower-priced plant products were to be regulated by CITES it would not be cost-effective for them to apply for permits and continue to trade the products. Three traders doubted the conservation effectiveness of the Appendix II CITES listing because of the difficulties in enforcing the regulations in many source countries. Two regarded the minimum size limit as ineffectual because of enforcement difficulties and the continued by-catch of seahorses in trawling.

Summary of perceived changes Most traders $(n=8)$ suggested that CITES control was the most significant cause of changes in trade patterns. Specifically, there was a reduction in supplies as a result of the domestic bans in the Philippines $(n=10)$ and India $(n=1)$, which they attributed to CITES. These decreases in supplies led to higher prices that, coupled with the time costs of permitting procedures $(n=4)$, led to lower profits $(n=4)$. Furthermore, with stricter implementation of the CITES regulations in Hong Kong, the trade shifted to mainland China and the re-export market from Hong Kong to mainland China decreased. Other factors considered to have affected trade were the establishment of direct trade between source countries and mainland China and Taiwan, and reduced local demand for seahorses. Also, the formation 
of the Chinese Medicine Council of Hong Kong led to significant policy changes in the local traditional Chinese medicine industry and stricter health standards and trade regulations.

\section{Government statistics (Hong Kong and Taiwan)}

Overview of declared source countries The number of declared source countries for seahorses traded into Hong Kong and Taiwan decreased between pre-listing (1998-2001) and post-implementation (2005-2007), whereas the number of source countries for pipefish did not (Table 2). During 1998-2007 most imports of seahorses declared in Hong Kong trade data were reportedly from the Philippines and Thailand, which between them accounted for $65-92 \%$ of the total declared imports (Supplementary Table $\mathrm{S}_{1}$ ). Hong Kong data also showed relatively large imports from Malaysia, Sri Lanka and Egypt during 1998-2007 but the declared volumes were not consistent from year to year and the majority of the total declared volume in this period was from a single year (Malaysia in 2004, Sri Lanka in 2005 and Egypt in 2004).

Total volume The reported mean annual volume of declared seahorse imports into Hong Kong decreased post-implementation relative to pre-listing (Table 2). There were also declines in the declared annual volumes of pipefish as well as seahorses into Taiwan but these were not statistically significant.

Domestic bans Domestic bans came into force postimplementation and led to declines in reported imports of seahorses into both Hong Kong and Taiwan from the Philippines and Peru. In contrast, there was no decline in declared import volumes of pipefish from the Philippines into Hong Kong. Hong Kong reportedly sourced $22-51 \%$ of the total declared annual import volumes of seahorses from the Philippines and Peru during the pre-listing period (1998-2001) but after 2004 only 1-3\% were from these two countries (Table 2). Peru was the only Latin American country consistently declared as a source for seahorses before implementation of the listing. Peru was also declared as a source for significant volumes of trade during the transition period. Although the decline in the declared volumes of seahorses into Hong Kong from Peru was not statistically significant, there were no declared seahorse imports from Peru after 2005. Pipefish were only declared to be from Peru during the transition period in 2003 and no seahorses were declared as imports from Peru to Taiwan during either the pre-listing or post-implementation periods. Although the CITES-independent domestic ban on the exploitation of syngnathids in India included both seahorses and pipefish, there was only a marginal, statistically insignificant decline in the declared volume of seahorses into Hong Kong and there was no statistically significant decline in the declared volume of pipefish from India (Table 2). There were no declared imports to Taiwan from India during the study period.

New source countries Data did not indicate an increase in the number of new source countries. Apart from Peru (with its domestic trade ban), Hong Kong Census and Statistics Department trade data indicated no significant changes in the total volume or number of declared Latin American or African source countries for seahorses between pre-listing and post-implementation. The data indicated that Senegal and Guinea accounted for $85 \%$ of the volumes from Africa. Peru was the only declared Latin American or African source country for pipefish during the study period. Seahorse imports into Taiwan from Latin America and Africa were reported only sporadically (from Suriname only in 2000 and from Egypt in 2006 and 2007; Supplementary Table $\left.\mathrm{S}_{3}\right)$.

Import price and economic value Declared import prices for seahorses increased in Hong Kong but there was no price increase for pipefish or seahorses imported into Taiwan. The declared unit values (in USD per $\mathrm{kg}$ ) for seahorses in Hong Kong doubled post-implementation compared to pre-listing (Fig. 1a). The prices of pipefish also appeared to increase post-implementation but this was not statistically significant (Fig. 1b). The declared import values of pipefish were lower than for seahorses throughout the study period (Fig. 1a,b). In contrast, the declared value of seahorses imported into Taiwan decreased (Fig. 1c). Although the declared import values of seahorses into Hong Kong and Taiwan were similar prior to the implementation of the listing, they were c. three times higher in Hong Kong than in Taiwan post-implementation (Fig. 1a,c). The declared total annual economic value of the seahorse trade fluctuated from year to year, with no apparent substantial changes among the pre-listing, transition and post-implementation periods for either seahorses or pipefish in Hong Kong (Fig. 1a,b). However, the total economic value of the seahorse trade in Taiwan decreased between the pre-listing and postimplementation periods (Fig. 1c).

Hong Kong re-exports The decline in the declared re-export volumes of seahorses from Hong Kong was not statistically significant. Pre-listing, Hong Kong re-exported large volumes of dried seahorses to mainland China (up to $26.8 \mathrm{t}$ annually). During the transition period, however, the total declared re-export volume from Hong Kong was $<10 \mathrm{t}$ per annum and the declared destinations were USA and Canada. Post-implementation, the total declared re-export increased, with most seahorses reportedly sent to Vietnam. Similarly, pre-implementation there were significant declared re-exports of pipefish to mainland China, Taiwan, Singapore and Malaysia. However, post- 

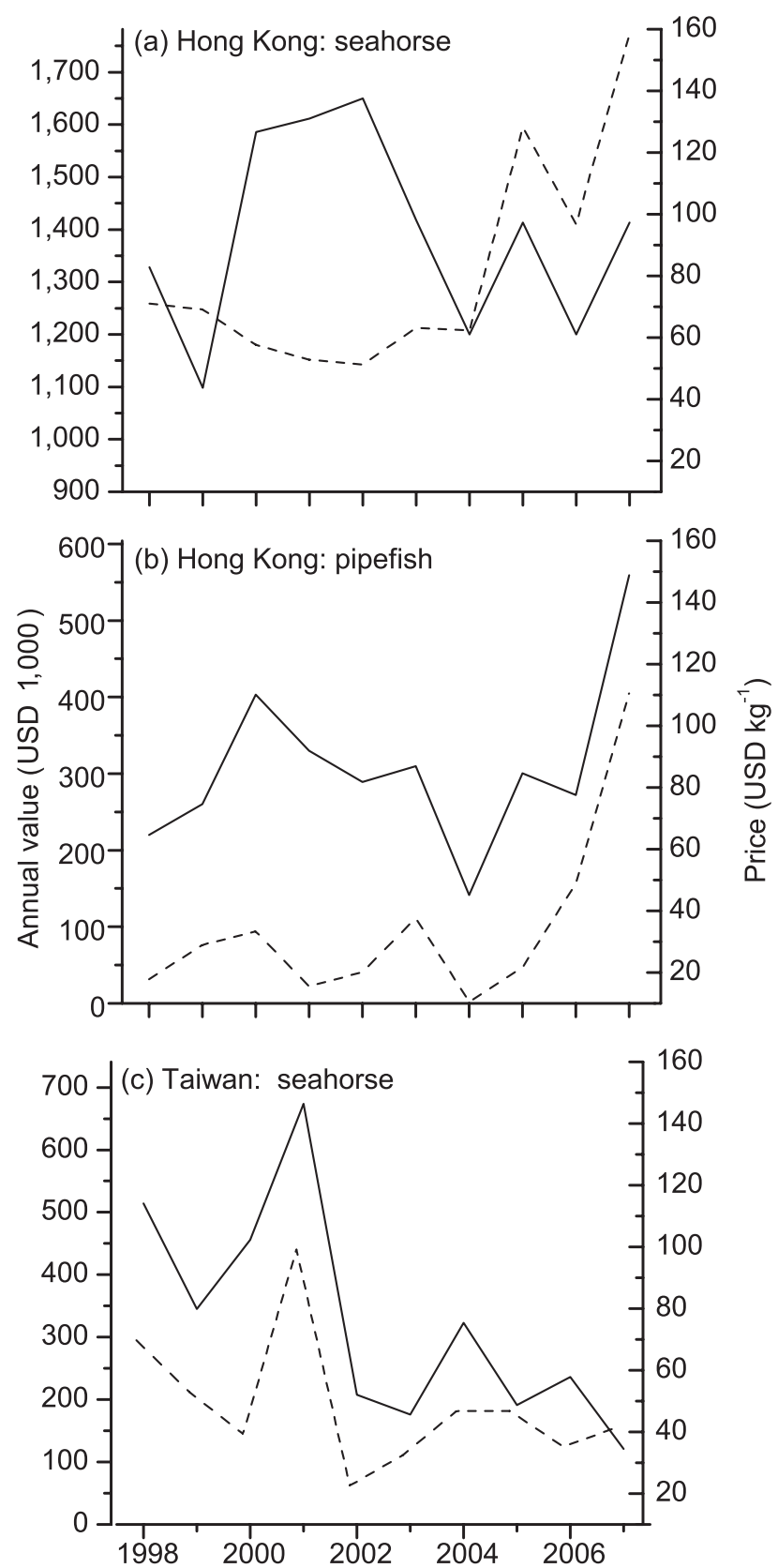

FIG.1 The declared price (USD kg ${ }^{-1}$, right axis, dashed line) and total value (kg, left axis, solid line) of seahorses (a) and pipefish (b) imported into Hong Kong and of seahorses imported into Taiwan (c), prior to the listing of seahorses in Appendix II of CITES in November 2002 and after formal implementation in May 2004.

implementation re-exports of pipefish from Hong Kong appeared to go only to North America.

\section{Discussion}

In this study we demonstrated how the perspectives of local stakeholders and formal trade statistics are complementary (Blundell \& Mascia, 2005). Interviews provided nuanced insights and putative explanations for changes, as well as the local background to the changes, that may affect trade dynamics and perceptions about the effects of CITES. The traders' understanding of the situation provided an insight into potential future changes in the trade, with concerns about overexploitation of seahorses, or Guangzhou supplanting Hong Kong as a major market-place for dried products in traditional Chinese medicine (possibly as a result of weaker implementation of CITES controls in mainland China). In contrast, formal statistics provided a broader picture of trade among regions, and quantify traders' understanding of change.

\section{Changes in trade patterns over time}

Both the interview data and the formal trade statistics indicate changes in source countries, decreases in imports, increases in the price of seahorses and decreases in reexports to mainland China during 1998-2007. The traders' impressions of changes in trade patterns were supported by formal statistics in terms of direction (positive or negative) although some opinions were not supported as statistically significant (Table 2), possibly because of the short time spans (4 years pre-listing and 3 years post-implementation). Such consistency across data sets enhances confidence in the findings. However, there was less consistency in relation to the magnitude of these changes, and whether or not the changes in volumes, source countries or prices were a consequence of CITES. For example, the traders suggested that there had been an increase in the number of trade routes and that the domestic bans (which they attributed to CITES) decreased supplies from key export countries. However, the trade statistics indicated decreases in the number of declared source countries, even when we excluded countries with domestic seahorse exploitation bans.

We found two specific disagreements on sourcing, related to the Philippines and mainland China. Both interview and formal data suggested that the decline in total import volumes of seahorses into Hong Kong could be partly attributed to the CITES-related seahorse exploitation ban in the Philippines. However, concurrent declines in imports of pipefish (not listed by CITES) to Hong Kong suggest other influences, such as declines in demand, declines in wild populations of seahorses and pipefish, or some form of trade linkage between seahorse and pipefish commerce. Secondly, traders suggested the CITES permitting procedure was onerous enough to lead traders to source more seahorses from within China and fewer from outside China. However, the trade statistics showed an overall decline in the number of imported seahorses both from within and outside China. If CITES-related permitting costs had led to reduced seahorse trade, one might have expected 
an increase in the trade volume of pipefish as traders switched to a less permit-intensive option with similar medicinal values. This was not the case.

\section{Seahorse prices}

Both interview data and trade statistics suggest increases in the unit price of seahorses imported into Hong Kong. The traders indicated that increases in price were a result of CITES-related decreased global supplies. However, the trade statistics also indicate increases in the price of nonCITES-listed pipefish and decreases in the price of seahorses in Taiwan. Traders suggested that trading seahorses had become less profitable because of increased prices (presumably because of the permitting process and domestic bans). However, trade data show only a minor decrease in annual economic value of seahorses imported into Hong Kong. The difference between the traders' perspectives and government statistics could indicate that there were more importers importing seahorses for uses other than traditional Chinese medicine (e.g. seafood importers) postimplementation or that the business costs of traders had increased. Moreover, it seems unlikely that the reduced economic value of seahorses in Hong Kong was a result of price increases; in Taiwan (where prices decreased), there was an even greater decline in the total annual value of seahorse imports. The decline in volume of trade for both seahorses and pipefish in Hong Kong suggests a factor beyond CITES but the coincidence of timing is surprising.

\section{Declines in re-exports}

Both the traders and the formal data reported that the total volume of seahorse re-exports from Hong Kong decreased after CITES implementation, but whether or not this decline was a result of the CITES listing is unclear. The decline in the declared re-exports of dried seahorses from Hong Kong to mainland China immediately after listing may support traders' perspectives that stricter CITES implementation in Hong Kong caused a shift in the trade away from Hong Kong to mainland China. However, Chinese customs statistics for mainland China indicate no increase in imports of seahorses from source countries into mainland China after 2001. The other possible explanation is that data on the re-export trade from Hong Kong to mainland China might be missing from official statistics: traders reported re-exporting $70 \%$ of their products to mainland China in 2007 but formal statistics indicate only $0.31 \%$ of re-exports going to mainland China in 2007 . Moreover re-exports of pipefish from mainland China to Hong Kong also declined.

\section{Summary of the effects of CITES}

Traditional Chinese medicine traders maintained that CITES had a greater negative effect on trade than indicated in the trade statistics, perhaps because of (1) proportionally higher imports of seahorses by seafood importers, (2) traders comparing import volumes to the transition period (when high volumes of trade occurred for seahorse imports into Hong Kong), or (3) confusion about the details of India's trade ban. Hong Kong traders blamed CITES for reduced supplies of seahorses, increased prices of seahorses, and wasted time and money for permits and licences. Traders indicated that these costs forced them to sell products locally in a region with declining local demand or seek out alternative non-CITES-listed medicinal products. In addition to maintaining that CITES caused an unfair loss of Hong Kong's position as a seahorse trading hub, traders considered that CITES was an ineffectual conservation measure because illegal or unreported trade would continue in mainland China or in source countries without effective enforcement.

Our research shows the value of using industry informants to complement government data and players (Burkhart et al., 2012). Parties must set frameworks for bottom-up multi-stakeholder dialogues to promote more effective monitoring and fair implementation of CITES and sustainable trade (Dongol \& Heinen, 2012). Whether or not the negative perceptions of CITES amongst Hong Kong traders are grounded in truth, their belief that CITES is costly, ineffective and unfairly implemented is a concern because Hong Kong's formal statistics depend on traders' support. Moreover, previous studies have indicated substantial quantities of illegal or undeclared trade through Hong Kong (e.g. CITES-listed turtles, Cheung \& Dudgeon, 2006; humphead wrasse Cheilinus undulatus, Poh \& Fanning, 2012).

Conducting surveys can be a cost-effective measure in major wildlife trading hubs such as Hong Kong, where a significant proportion of the global trade in a wildlife product is channelled through only a few importers (Karesh et al., 2007). Here we were able to analyse imports of millions of seahorses into Hong Kong (Evanson et al., 2011). Although our work has focused on importers in a major importing bottleneck, the proposal that interviews with traders be a central part of CITES analyses is even more relevant in major exporting centres. Hong Kong is unusual in keeping CITES records of imports. However, CITES documentation is mandatory for Parties that export any wild fauna or flora listed in a CITES Appendix. There are other key wildlife exporting hubs in regions such as West Papua, Indonesia (for amphibians and reptiles; Natusch \& Lyons, 2012) and Peru (for parrots; Gastañaga et al., 2011) where interviews with a small number of major exporters could facilitate rapid comparisons with official trade 
statistics to gain insight into the socio-economic or ecological effects of different national implementations of CITES listings.

Given that seahorses were the first fishes to be listed by CITES following its inception, international support is essential to ensure an effective outcome. Our methods and results may help enhance monitoring and stakeholder engagement, both of which are crucial to the success of CITES and conservation of marine species.

\section{Acknowledgements}

This is a contribution from Project Seahorse. We are grateful to anonymous referees, Boris Kwan, Samuel Lee, Timothy $\mathrm{Ng}$ Sau Kin (Ocean Park Conservation Foundation), Craig Kirkpatrick (formerly TRAFFIC East Asia), Yvonne Sadovy (University of Hong Kong), Tsang Chiu Hing (HKCMMA), Alfred KC Wong (Agriculture, Fisheries and Conservation Department), Shen Jian Gang (University of Hong Kong), Tamara Trafton and Negar Elmieh (Quest University Canada) and members of the Project Seahorse team for support and comments. We received financial support from the Wallace Global Fund, John G. Shedd Aquarium, Guylian Chocolates and an NSERC Post-doctoral Fellowship.

\section{References}

Blundell, A.G. \& MAscia, M.B. (2005) Discrepancies in reported levels of international wildlife trade. Conservation Biology, 19, 2020-2025.

Burkhart, E.P., Jacobson, M.G. \& Finley, J. (2012) A case study of stakeholder perspective and experience with wild American ginseng (Panax quinquefolius) conservation efforts in Pennsylvania, USA: limitations to a CITES driven, top-down regulatory approach. Biodiversity and Conservation, 21, 3657-3679.

Cheung, S.M. \& Dudgeon, D. (2006) Quantifying the Asian turtle crisis: market surveys in southern China, 2000-2003. Aquatic Conservation: Marine and Freshwater Ecosystems, 16, 751-770.

Christie, P., Oracion, E.G. \& Eisma-Osorio, L. (2011) Impacts of the CITES Listing of Sea Horses on the Status of the Species and on Human Well-being in the Philippines. FAO Fisheries and Aquaculture Circular No. 1058, FAO, Rome, Italy.

CITES (1979) Convention on International Trade in Endangered Species of Wild Fauna and Fora. Http://www.cites.org/eng/disc/text. php\#II [accessed 25 May 2014].

CITES (2004) Seahorses and Other Members of the Family Syngnathidae (Decision 12.54): Report of the Workign Group. Http://www.cites.org/eng/com/ac/20/E20-17.pdf [accessed 25 May 2014].

Dongol, Y. \& Heinen, J.T. (2012) Pitfalls of CITES implementation in Nepal: a policy gap analysis. Environmental Management, 50, 181-190.

Doukakis, P., Parsons, E.C.M., Burns, W.C.G., Salomon, A.K., Hines, E. \& Cigliano, J.A. (2009) Gaining traction: retreading the wheels of marine conservation. Conservation Biology, 23, 841-846.
Evanson, M.E., Foster, S.J., Wiswedel, S. \& Vincent, A.C.J. (2011) Tracking the international trade of seahorses (Hippocampus species). Fisheries Centre Research Reports, 19, 1-92.

Ferraro, P.J., McIntosh, C. \& Ospina, M. (2007) The effectiveness of the US Endangered Species Act: an econometric analysis using matching methods. Journal of Environmental Economics and Management, 54, 245-261.

Ferraro, P.J. \& Pattanayak, S.K. (2006) Money for nothing? A call for empirical evaluation of biodiversity conservation investments. PLoS Biology, 4(4), e105.

Foster, S.J. \& VinCENT, A.C.J. (2005) Enhancing sustainability of the international trade in seahorses with a single minimum size limit. Conservation Biology, 19, 1044-1050.

Gastañaga, M., Macleod, R., Hennessey, B., Nuñez, J.U., Puse, E., Arrascue, A. et al. (2011) A study of the parrot trade in Peru and the potential importance of internal trade for threatened species. Bird Conservation International, 21, 76-85.

Karesh, W.B., Cooke, R.A., Gilbert, M. \& Newcomb, J. (2007) Implications of wildlife trade on the movement of avian influenza and other infectious diseases. Journal of WIldlife Diseases, 43, $\mathrm{S}_{55}-\mathrm{S}_{59}$.

Lourie, S.A., Foster, S.J., Cooper, E.W.T. \& Vincent, A.C.J. (2004) A Guide to the Identification of Seahorses. Project Seahorse, University of British Columbia, Canada, and TRAFFIC North America, Washington, DC, USA.

Natusch, D.J.D. \& Lyons, J.A. (2012) Exploited for pets: the harvest and trade of amphibians and reptiles from Indonesian New Guinea. Biodiversity and Conservation, 21, 2899-2911.

Nijman, V. \& Shepherd, C.R. (2007) Trade in non-native, CITESlisted wildlife in Asia, as exemplified by the trade in freshwater turtles and tortoises (Chelonidae) in Thailand. Contributions to Zoology, 76, 207-211.

Poh, T.-M. \& Fanning, L.M. (2012) Tackling illegal, unregulated, and unreported trade towards humphead wrasse (Cheilinus undulatus) recovery in Sabah, Malaysia. Marine Policy, 36, 696-702.

R Development Core Team (2012) R: A Language and Environment for Statistical Computing. R Foundation for Statistical Computing, Vienna, Austria.

Reeve, R. (2006) Wildlife trade, sanctions and compliance: lessons from the CITES regime. International Affairs, 82, 881-897.

Shuman, C.S., Hodgson, G. \& Ambrose, R.F. (2005) Population impacts of collecting sea anemones and anemonefish for the marine aquarium trade in the Philippines. Coral Reefs, 24, 564-573.

Smith, M.J., Benítez-Díaz, H., Clemente-Muñoz, M.A., Donaldson, J., Hutton, J.M., McGough, H.N. et al. (2011) Assessing the impacts of international trade on CITES-listed species: current practices and opportunities for scientific research. Biological Conservation, 144, 82-91.

Sreepada, R.A., Desai, U.M. \& Naik, S. (2002) The plight of Indian sea horses: need for conservation and management. Current Science, $82,377-378$.

Vincent, A.C.J. (1996) The International Trade in Seahorses. TRAFFIC International, Cambridge, UK.

Vincent, A.C.J., Foster, S.J. \& Koldewey, H.J. (2011) Conservation and management of seahorses and other Syngnathidae. Journal of Fish Biology, 78, 1681-1724.

Winter, S., Penker, M. \& Kriechbaum, M. (2011) Integrating farmers' knowledge on toxic plants and grassland management: a case study on Colchicum autumnale in Austria. Biodiversity and Conservation, 20, 1763-1787.

Zhang, H.C., QING, L.P. \& Zhang, E.D. (2000) Conservation of Endangered Wildlife Species Used in Traditional Chinese Medicine. Second Military Medical University Press, Shanghai, China. 


\section{Biographical sketches}

Joy LAM is interested in the trading and consumption of marine species, as well as conservation mechanisms such as marine protected areas. Heather Koldewey's research is focused on informing conservation action, and ranges from threatened species to the ecosystem level. MAÏ YASUÉ is interested in how to create fair and effective conservation projects in the developing world. AMANDA VINCENT has broad research interests focused on seahorses as iconic marine species. Her work ranges from biology to gender studies to policy development and aims to integrate academic research into practical approaches to marine conservation. 